\title{
BMJ Open Factors associated with the utilisation of primary care services: a cross-sectional study in public and private facilities in Albania
}

Jonila Gabrani (D) , ${ }^{1,2}$ Christian Schindler, ${ }^{3}$ Kaspar Wyss ${ }^{1,2}$

To cite: Gabrani J, Schindler C, Wyss K. Factors associated with the utilisation of primary care services: a cross-sectional study in public and private facilities in Albania. BMJ Open 2020;10:e040398. doi:10.1136/ bmjopen-2020-040398

- Prepublication history for this paper is available online. To view these files, please visit the journal online (http://dx.doi. org/10.1136/bmjopen-2020040398).

Received 15 May 2020

Revised 21 August 2020 Accepted 20 0ctober 2020
D) Check for updates

(c) Author(s) (or their employer(s)) 2020. Re-use permitted under CC BY-NC. No commercial re-use. See rights and permissions. Published by BMJ.

${ }^{1}$ Swiss Centre for International Health, Swiss Tropical and Public Health Institute, Basel, Switzerland

${ }^{2}$ Faculty of Medicine, University of Basel, Basel, Switzerland ${ }^{3}$ Epidemiology and Public Health EPH, Swiss Tropical and Public Health Institute, Basel, Switzerland

\section{Correspondence to} Jonila Gabrani; jonila.gabrani@swisstph.ch; jonila.gabrani@unibas.ch

\section{ABSTRACT}

Objectives To identify key factors influencing the utilisation of governmental and private primary healthcare services in Albania.

Design A cross-sectional health facility survey using a 4-point Likert scale questionnaire to rank the importance of factors driving services utilisation.

Setting Exit interviews with patients who consulted one of 23 primary care providers (18 public and 5 private) in Fier district of Albania from the period of July-August 2018 . Participants Representative sample of 629 adults $\geq 18$ years of age.

Main outcomes measures (1) Factors influencing the decision to visit a governmental or private primary care provider and (2) the association of sociodemographic characteristics and patients' decision to attend a given provider. Data were analysed using mixed logistic regression models.

Results Nearly half of the participants in this study were older than 60 years $(45 \%)$. The majority $(63 \%)$ reported to suffer from a chronic condition. Prevailing determinants for choosing a provider were 'quality of care' and 'healthcare professionals' attitudes. Solely looking at patients using a public provider, 'geographical proximity' was the most important factor guiding the decision $(85 \%$ vs $11 \%$, $p<0.001)$. For private provider's patients, the 'availability of diagnostic devices' was the most important factor $(69 \%$ vs $9 \%, p<0.001)$. The odds of using public facilities were significantly higher among the patients who perceived their health as poor (OR 5.59; 95\% $\mathrm{Cl} 2.62$ to 11.92), suffered from chronic conditions (OR $3.13 ; 95 \% \mathrm{Cl} 1.36$ to 7.24) or were benefiting from a socioeconomic aid scheme (OR 3.52; $95 \% \mathrm{Cl} 1.64$ to 7.56 ).

Conclusion The use of primary healthcare is strongly influenced by geographical and financial access for public facility users and availability of equipment for private users. This study found that aspects of acceptability and adequacy of services are equally valued. Additional commitment to further develop primary care through engagement of local decision-makers and professional associations is needed.

\section{BACKGROUND}

Access to public primary healthcare (PHC) enables patients and physicians to prevent and better manage illness, while limiting the
Strengths and limitations of this study

- In the context of a growing importance of the private sector, this study informs on the reasons for the use of private and public services in a mostly rural setting in Albania.

- This study contributes to a better understanding of the individual and health system provider-related factors associated with the use of healthcare services. Thus, factors of operational relevance for improving primary care and strengthening the health system are decorticated.

- The study covered representative sample of users of primary care in one region and included 18 public facilities and 5 private settings.

- The study was relying on self-reporting perceptions rather than measurements of an impartial observer; therefore, possible variations of the patients' perceived importance may be attributed to differences in patients' characteristics, cultural aspects, previous experience and expectations rather than actual provider practice.

- The region where the study was conducted reflects generalised patterns of Albania but cannot be considered as fully representing the sociocultural and economic diversity of the country. Consequently, we cannot exclude the possibility that if applied to other regions, the results would differ.

cost of health service provision and protecting patients from financial hardship related to health. ${ }^{1-4}$

As an extension of choice between different treatments and to access reliable services that are responsive to patients' preferences, there are also the private providers, which are indeed an important source of healthcare and have a role to play in delivering good and affordable health services. Though there is an array of theoretical research on factors enabling or hindering the uptake of such services, ${ }^{5-12}$ little is known what motivates and drives utilisation of public and private PHC services in rural settings in Albania. 
Albania, a south East-European postcommunist country, with a health system in transition, ${ }^{13}$ has undertaken initial steps in strengthening the role of PHCs services. In 2015 a national free check-up programme for those 45 years and older as well as free access to preventive services for the entire population was introduced. Despite these strategic actions which have generated positive trends in terms of PHC utilisation, there is concern that these trends might diminish due to a lack of culture of prevention, inherited from the old 'curative' health system ${ }^{14}$ and due to ill-equipped facilities, which indeed, often push patients to bypass PHC in favour of specialty care or private providers. ${ }^{1416}$

In Albania, private outpatient providers have experienced, massive growth over the last two decades, principally in large urban settings of Tirana. They offer a full range of medical services, starting from diagnostics and providing more comprehensive treatment and support, duplicating the functions of both public PHC clinics and polyclinics of specialties. Most of these services are also provided by public PHC as delineated among else to the recent PHC basic package of services. ${ }^{17}$ However, evidence on the determinants of utilisation of public PHC and private facilities associated with the utilisation of each provider type, is currently missing, including in respect to patterns in rural settings and secondary cities.

Governmental PHC care plays an important role in immunisation and reproductive health. The expectations of what PHC should achieve in the near future regarding the prevention, treatment and management of noncommunicable diseases (NCDs) are delineated and indorsed in different strategic national documents, as an effective response to the Albanian health system challenges, such as continuous raise of NCDs and ageing population. ${ }^{18-20}$ Access to most public services is free and there are generally no fees at the point of use (PHC), whereas the private sector generally requires out of pocket payments or possession of private health insurance. ${ }^{17}$ The model of the health insurance scheme in the Republic of Albania is a mix model, based on mandatory and voluntary contributions, as well as funding from the state budget. The economically active population pays for state health insurance, while the state budget through general taxation covers the inactive population and the categories in need, thus giving the scheme a solidarity approach. The mechanism for implementing the health insurance scheme is based on annual contracts between the health insurance fund with public and certain private health service providers for the provision of a defined health service package. The health insurance scheme covers: (1) Primary service; (2) Hospital service ; (3) List of reimbursable drugs. Compulsory health insurance finances an essential service package, which includes: visits, examinations and medical treatments in public PHC centres and public hospitals; visits, examinations and medical treatments in certain contracted private primary care providers and private hospitals; medicines, products and medical treatments from contracted healthcare providers. ${ }^{21}$
Meanwhile, private healthcare services consist mostly of private for-profit health services organisations or faithbased facilities which deliver outpatient care. Across the country, there are as per 2020, 10 private hospitals; 229 specialised private diagnostic and laboratory centres; and 177 outpatient medical centres and cabinets, principally situated in urban areas. ${ }^{22}$

Too often research on PHC is focused on measuring inputs to care-including supplies, infrastructure and financing-while ignoring the core functions of service delivery as experienced by users of the system ${ }^{23}$ which are indeed an important consideration in health service research for policy and planning reasons. ${ }^{24}$ This study assesses factors motivating patients to use governmental PHC and outpatient private clinics and possible sociodemographic (individual) characteristics associated with the attendance of public PHC and private clinics.

\section{Drivers of health services utilisation in public and the private settings}

Patients' choice to use a public or a private facility within a health system with a diversity of providers is guided by a range of factors. Researchers have identified factors which relate to:

1. Individual characteristics using the service such as: health status, knowledge and beliefs as well as sociodemographic and socioeconomic characteristics. ${ }^{5-7} 2425$

2. Service provider characteristics, including ownership, size, service type, accreditation and reputation of the respective institution.

3. Patients' perceptions of the quality of services provided along with health service providers' 'responsiveness are key factors in determining the use of the healthcare facility. In fact, quality of care as a determinant for choosing healthcare providers has been gaining grounds over the past decades. ${ }^{26-28}$

Good access to healthcare services is seen as key driver for increasing utilisation of services. Access, defined as a measure of the proportion of the population that reaches appropriate health services, is a complex and multidimensional concept susceptible to various frameworks and interpretations. ${ }^{5-10}$ Theoretical research related to access in healthcare has historically been influenced by the Andersen model of predisposing (eg, age, sex and social structure), enabling (eg, distance to healthcare) and need (eg, symptoms and functioning) factors. ${ }^{5}$

Other authors have emphasised the need to more strongly focus on the dynamics of access and have elaborated on five abilities of populations to interact with the dimensions of accessibility: ability to perceive and to seek care; ability to reach, to pay and to engage with healthcare services. ${ }^{8}$ Still other authors have stressed that access framework should further embed 'awareness' as an integral part of access. ${ }^{9}$

In this study, we use the concept of access first elaborated by Penchansky and Thomas, ${ }^{6}$ which summarises a set of dimensions describing the fit between the patient and the healthcare system (figure 1). The specific 


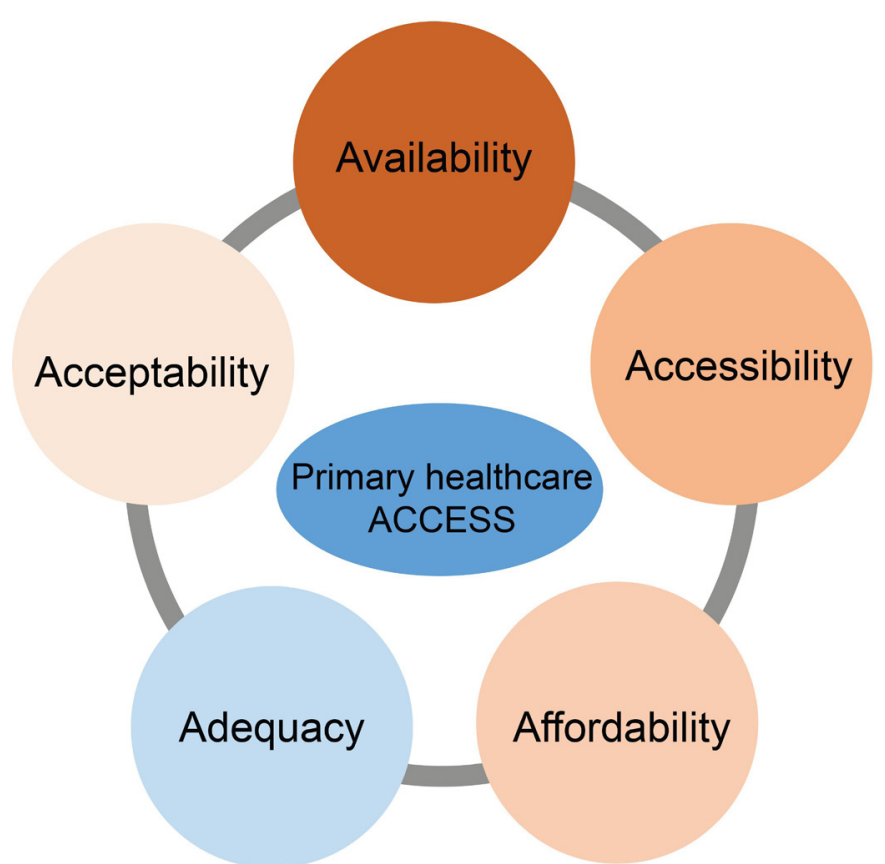

Figure 1 The concept of access: definition and relationship to consumer satisfaction. Adapted from Penchansky and Thomas. ${ }^{6}$ Concept of access first elaborated in 1981.

dimensions of the framework are further operationalised by Obrist et $a l^{29}$ namely: Access, Availability, Affordability, Adequacy and Acceptability (table 1).

What guides patients' decision to use outpatient private services which are also offered by the public sector is poorly understood. ${ }^{30}$ However, problems of quality and accessibility of the public sector alongside with difunctional medical equipment have been identified as drivers for the use of private clinics. ${ }^{25}$ 31-34 The private for-profit sector positions itself as a driver of innovation, a provider of higher quality care, able to offer greater efficiency and improved access via new delivery models. ${ }^{35} 36$

There is still limited information on the demand side available in the literature, specifically on how individuals choose healthcare services and the prevailing characteristics of the providers when deciding to consult a given type of provider according to patients 'view.

\section{Goals of this study}

The present study has two objectives:

a. To analyse factors influencing utilisation of public funded PHC and private facilities, as viewed by patients.

b. To analyse the association of service utilisation by provider type with the sociodemographic and health characteristics of the respondents.

\section{METHODS Study design}

A cross-sectional representative patient exit survey was conducted in one region of Albania. The study used faceto-face interview to collect data from patients attending both public PHC centres and private outpatient clinics. The focus of the structured interview was on personal characteristics, health service-related views and priorities of patients.

\section{Setting and sampling}

The study was conducted in urban and rural areas of Fier region in Albania. The region is located $98 \mathrm{~km}$ southwest of Albania with access to the seaside. The most recent census 2011 registered 310277 persons living in in Fier. Patients who sought care were included in the sample with a probability proportional to healthcare utilisation numbers in 2017. Thus, the study covered all 18 public PHCs and the 5 out of 8 licensed private outpatient clinics who agreed to participate. Adults of more than 18 years of age were interviewed through an exit interview after their visit. Inclusion criteria for the health facilities were as follows: (1) public and private health facilities, (2) at least one medical doctor working at the facility and (3) provision of care and prevention related to chronic diseases (eg, diabetes mellitus, hypertension). Inclusion criteria for an exit interview with a patient were: (1) patients, either 18 years or older or accompanied by a legal representative

Table 1 The dimensions of access to healthcare services according to the ACCESS Framework

\begin{tabular}{|c|c|c|}
\hline Dimension & Definition & Aspects to consider \\
\hline Availability & $\begin{array}{l}\text { 'The existing health services and } \\
\text { goods meet clients' needs.' }\end{array}$ & $\begin{array}{l}\text { Adequate supply of services, goods and facilities, including types of } \\
\text { services, sufficient skilled human resources. }\end{array}$ \\
\hline Affordability & $\begin{array}{l}\text { 'The prices of services fit the } \\
\text { clients' income and ability to pay.' }\end{array}$ & Direct and indirect costs of accessing healthcare. \\
\hline Acceptability & $\begin{array}{l}\text { 'The characteristics of providers } \\
\text { match with those of the clients.' }\end{array}$ & $\begin{array}{l}\text { Ethical standards and the appropriateness of services, goods and } \\
\text { facilities to address cultural and gender differences and life-cycle } \\
\text { requirements; to improve outcomes; and to ensure confidentiality, } \\
\text { effective communication and facilitating attitudes. }\end{array}$ \\
\hline
\end{tabular}

Dimensions of the framework further operationalised by Obrist et al. ${ }^{29}$ 
accessing the health facility and receiving consultation from a health provider and (2) written informed consent of the patient or her/his's legal representative.

\section{Method of measurements, the development of the questionnaires}

A structured questionnaire was developed to collect data on (1) patients' sociodemographic characteristics and (2) principal reasons behind utilisation of each facility.

The questions addressed patients' sociodemographic characteristics such as age, gender, employment status, education, status of health insurance; patients' health conditions were also collected including self-reported health status (poor/not poor), presence of chronic health condition (yes/no).

Then, patients were asked to rank the importance of the 12 items (questions). The 12-item questionnaire was developed based on the five dimension of the ACCESS framework ${ }^{62}$ : (see table 1) covering aspects of geographic and financial accessibility, availability, affordability, adequacy and acceptability.

The dependent variable was the utilisation of publicly funded PHC or private facilities. The independent variables were the sociodemographic characteristics of the study participants such as gender, age, health insurance.

In order to assure content validity of the questionnaire, a pretesting was done. After the pretest, we received the interviewer feedback and minor adjustments were made to the wording of questions as well as the pre-defined answers. Finally, a panel of four staff, compounded of a one public health specialist, one academic staff and two operational managers, reviewed the questionnaire and made comments and suggestions.

Secondary outcomes were descriptively assessed by questions such as 'for what health-related condition did the patient consult the facility today'; if they had 'consulted a doctor working in the public health sector before (yes/no)'; 'how many times had they attended the facility over the last 3 months' and 'how often had they been referred in other public/private medical institutions by their doctor over the last 3 months'.

Questionnaires were translated from English to Albanian. To assure the accuracy of the translation, questionnaires were translated into Albanian and back-translated.

\section{Data collection}

Data collection took place from July to August 2018. The face-to-face interviews were conducted respecting privacy of patients. Interviews were conducted by the Faculty of Medicine students with a bachelor or upper level education; interviewers were trained for 3 days before actual data collection. Data collection was done electronically using tablets. The questionnaire software used for this study was Open Data Kit. The data collected from the questionnaires was transferred to a server in Basel, Switzerland on the same day where an initial quality check was regularly conducted.

\section{Data analysis}

In a first step, patients' sociodemographic characteristics were analysed across the two types of health facilities and described respectively. For certain characteristics, such as health status, data were collected on a 4-point Likert scale (with $1=$ good, $2=$ rather good, $3=$ rather poor and $4=$ =oor). In order to facilitate analysis, the health rate was then dichotomised as good and poor health. Next, patients' ratings of the importance of each item influencing their decision for consultation at the respective type of facility were recorded on a 4-point Likert scale (with 1=not important at all, 2=not important, 3=importantand $4=$ very important). Scales were then dichotomised by collapsing categories 1 and 2 into ' $0=$ not important' and categories 3 and 4 into ' 1 =important'. Dichotomised items were compared in terms of percentage of positive agreements between public and private facilities using $\chi^{2}$ tests. The test was performed on a $5 \%$ level of significance, indicating the existence of differences between the type of providers (public and private) for each aspects of access attributes. In these simple comparisons, we also looked for potential geographical clustering differences. Sociodemographic factors potentially associated with a patient's decision for a specific provider were selected as explanatory variables. The dichotomous dependent variable was the type of healthcare facility used: public PHC centre versus private outpatient clinic.

Then, mixed logistic regression models with random intercepts for the three different communities (Lushnje, Fier, Mallakaster) were used to assess the associations of sociodemographic variables with the facility type used. Results are reported as ORs along with 95\% CIs. Results with a $\mathrm{p}<0.05$ were considered statistically significant. Data were analysed using Stata Statistical Software, V.15.

\section{Patient and public involvement}

During the pretest, we received the interviewers' feedback from the interaction with the patients in the fieldwork. The questionnaire was updated based on the outcome of the pretest.

\section{RESULTS}

\section{Patients' characteristics by type of healthcare provider} considerations

Out of 750 eligible study participants, 629 accepted to be interviewed corresponding to a response rate of $84 \%$. Table 2 shows the sociodemographic and health profile of the patients participating in the study, by type of facility. The sample consisted of 250 males $(40 \%)$ and 379 females $(60 \%)$. Forty-five per cent of the respondents were more than 60 years old. Around four-fifths (77\%) of the respondents had a valid health insurance card and $18 \%$ were currently benefiting from a form of social or economic aid. With regard to education, $47 \%$ of the respondents had an elementary education (5-8 years) and $14 \%$ of the respondents had a college or university degree. 
Table 2 Patients' characteristics on sociodemographic and health measures by type of healthcare provider

\begin{tabular}{|c|c|c|c|c|c|c|}
\hline \multirow[b]{2}{*}{ Characteristics } & \multicolumn{2}{|c|}{$\begin{array}{l}\text { Total } \\
\text { population }\end{array}$} & \multicolumn{2}{|c|}{$\begin{array}{l}\text { Public PHC } \\
\text { clinics }\end{array}$} & \multicolumn{2}{|c|}{$\begin{array}{l}\text { Private } \\
\text { outpatient } \\
\text { clinics }\end{array}$} \\
\hline & $\mathbf{N}$ & $\%$ & $\mathbf{N}$ & $\%$ & $\mathbf{n}$ & $\%$ \\
\hline Gender & 629 & & 451 & & 178 & \\
\hline Male & 250 & 40 & 186 & 41 & 64 & 36 \\
\hline Female & 379 & 60 & 265 & 59 & 114 & 64 \\
\hline Age & 624 & & 449 & & 175 & \\
\hline$<59$ years old & 344 & 55 & 240 & 53 & 104 & 59 \\
\hline$\geq 60$ years old & 280 & 45 & 209 & 47 & 71 & 41 \\
\hline Education & 512 & & 343 & 67 & 169 & 33 \\
\hline University/college & 74 & 14 & 46 & 13 & 28 & 16 \\
\hline High school (12 years) & 187 & 37. & 125 & 37 & 62 & 37 \\
\hline $\begin{array}{l}\text { Primary and secondary } \\
\text { school (5-9 years) }\end{array}$ & 242 & 47 & 164 & 48 & 78 & 46 \\
\hline Iliterate/other & 9 & 2 & 8 & 2 & 1 & 1 \\
\hline Occupation & 554 & & 386 & 70 & 168 & 30 \\
\hline Employed & 151 & 27 & 98 & 26 & 53 & 32 \\
\hline Unemployed & 182 & 33 & 125 & 32 & 57 & 34 \\
\hline Pensioner & 221 & 40 & 163 & 42 & 58 & 34 \\
\hline Health rate & 629 & & 451 & 72 & 178 & 28 \\
\hline Poor & 145 & 23 & 134 & 29 & 11 & 6 \\
\hline Good & 484 & 77 & 317 & 70 & 167 & 94 \\
\hline Health Insurance & 629 & & 451 & 72 & 178 & 28 \\
\hline No & 142 & 23 & 84 & 19 & 58 & 33 \\
\hline Yes & 487 & 77 & 367 & 81 & 120 & 67 \\
\hline $\begin{array}{l}\text { Benefit socioeconomic } \\
\text { aid }\end{array}$ & 629 & & 451 & 72 & 178 & 28 \\
\hline No & 515 & 82 & 348 & 77 & 167 & 94 \\
\hline Yes & 114 & 18 & 103 & 23 & 11 & 6 \\
\hline Chronic conditions & 629 & & 451 & 72 & 178 & 28 \\
\hline 0 & 231 & 37 & 155 & 34 & 76 & 43 \\
\hline 1 & 279 & 44 & 192 & 43 & 87 & 49 \\
\hline Two or above & 119 & 19 & 104 & 23 & 15 & 8 \\
\hline $\begin{array}{l}\text { Years suffering from } \\
\text { NCDs }\end{array}$ & 379 & & 277 & 73 & 102 & 27 \\
\hline $2(\leq 2)$ years & 87 & 23 & 55 & 20 & 32 & 31 \\
\hline$>2$ years & 292 & 77 & 222 & 80 & 70 & 69 \\
\hline $\begin{array}{l}\text { No of times facility } \\
\text { attended }\end{array}$ & 629 & & 451 & & 178 & \\
\hline$\leq 1$ & 140 & 22 & 82 & 18 & 58 & 33 \\
\hline$\geq 2$ & 489 & 78 & 369 & 82 & 120 & 67 \\
\hline
\end{tabular}

NCDs, non-communicable diseases; PHC, primary healthcare.

\section{Characteristics of patients using public and private services}

In regards to the health-related characteristics of the respondents, more than two-thirds $(63 \%)$ of the respondents reported that they had suffering from at least one chronic illness and about one quarter of them $(29 \%$ in public clinics and $6 \%$ in private) perceived their health
Cleanliness and tidiness of the facility Privacy and personal information respected Health information Possibility to choose the doctor Qualified health staff Medical equipments

Health insurance Staff courtesy Cost of service affordable Quality of service Waiting time Location of the health facility

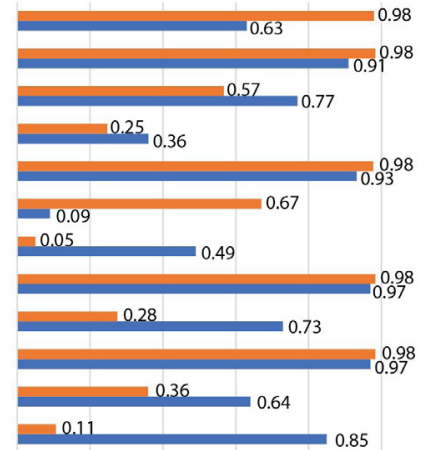

- Private outpatient $\quad$ Public PHC

Figure 2 Principal reasons for using healthcare facility type†. †Percentage of positive agreements were obtained by patients 'ratings of each item as 'important' or 'very important' when consulting public and private facilities. PHC, primary healthcare.

status to be poor. The percentage of patients who reported suffering from two or more chronic conditions was higher in public PHC clinics $(23 \%)$ compared with private clinics $(8 \%)$, while the proportion of patients who were diagnosed with a chronic condition less than 2 years ago was higher in private clinics $(31 \%)$ compared with the governmental PHC facilities (20\%). Patients using governmental $\mathrm{PHC}$ clinics reported an average of 3 visits to the health facility over the past 3 months compared with 2.5 visits among patients attending private clinics (data not shown).

The main reason for accessing healthcare facilities was related to patients' chronic health conditions $(54 \%$ in public vs $44 \%$ in private facilities). A greater proportion of patients attending public PHCs reported that they were often referred to another provider (eg, specialist) for complementary examinations as compared with those attending private providers (70\% vs $23 \%)$. Around $85 \%$ of patients attending private $\mathrm{PHC}$ indicated that they consulted a doctor working in the public health sector before attending the private facility.

\section{Factors influencing patients' choice for a specific provider type consultation}

Figure 2 shows the responses of the study participants on the importance of different provider-related factors which influenced them to use the respective type of healthcare facility.

Items considered as important by patients of both types of providers were 'quality of care', and 'healthcare professionals' attitudes' being both qualified and courteous (see figure 2). The high importance for the respective items implies that these factors are the strongest ones influencing and possibly driving health facility utilisation. Items considered as least important 'possibility to choose doctor', 'wait time' and 'health insurance'

There were significant differences between the two patient groups regarding the importance attributed to items such as the 'location of the facility', 'availability of 
Table 3 Principal reasons for using the health facility type (rating of items as 'important' or 'not important')

\begin{tabular}{|c|c|c|c|c|c|c|c|c|}
\hline \multirow[b]{2}{*}{ Variables } & \multicolumn{2}{|c|}{ Total population } & \multicolumn{2}{|c|}{ Public PHC } & \multicolumn{2}{|c|}{$\begin{array}{l}\text { Private outpatient } \\
\text { clinics }\end{array}$} & \multirow[t]{2}{*}{ P value* } & \multirow[t]{2}{*}{ P value $†$} \\
\hline & $\mathbf{N}$ & $\%$ & $\mathbf{N}$ & $\%$ & $\mathbf{N}$ & $\%$ & & \\
\hline No & 227 & 36 & 68 & 15 & 159 & 89 & $<0.001$ & $<0.001$ \\
\hline Yes & 402 & 64 & 383 & 85 & 19 & 11 & & \\
\hline Waiting time & 629 & & 451 & 71.7 & 178 & 28.3 & & \\
\hline Yes & 352 & 56 & 288 & 64 & 64 & 36 & & \\
\hline Quality of service & 629 & & 451 & 71.7 & 178 & 28.3 & & \\
\hline No & 15 & 2 & 12 & 3 & 3 & 2 & 0.5 & 0.7 \\
\hline Yes & 614 & 98 & 439 & 97 & 175 & 98 & & \\
\hline Staff courtesy & 629 & & 451 & 71.7 & 178 & 28.3 & & \\
\hline No & 18 & 3 & 15 & 3 & 3 & 2 & 0.3 & 0.4 \\
\hline Yes & 611 & 97 & 436 & 97 & 175 & 98 & & \\
\hline Health insurance & 629 & & 451 & 71.7 & 178 & 28.3 & & \\
\hline No & 399 & 63 & 229 & 51 & 170 & 96 & $<0.001$ & $<0.001$ \\
\hline Yes & 230 & 37 & 222 & 49 & 8 & 4 & & \\
\hline Medical devices & 629 & & 451 & 71.7 & 178 & 28.3 & & \\
\hline No & 465 & 74 & 409 & 91 & 56 & 33 & $<0.001$ & $<0.001$ \\
\hline Yes & 164 & 26 & 42 & 9 & 122 & 67 & & \\
\hline Availability of health information & 629 & & 451 & 71.7 & 178 & 28.3 & & \\
\hline No & 180 & 29 & 103 & 23 & 77 & 43 & $<0.001$ & $<0.001$ \\
\hline Yes & 449 & 71 & 348 & 77 & 101 & 57 & & \\
\hline Privacy respected & 629 & & 451 & 71.7 & 178 & 28.3 & & \\
\hline No & 43 & 7 & 40 & 9 & 3 & 2 & 0.001 & 0.01 \\
\hline Yes & 586 & 93 & 411 & 91 & 175 & 98 & & \\
\hline Cleanliness of the facility & 629 & & 451 & 71.7 & 178 & 28.3 & & \\
\hline No & 167 & 27 & 165 & 37 & 2 & 2 & $<0.001$ & $<0.001$ \\
\hline Yes & 462 & 73 & 286 & 63 & 176 & 98 & & \\
\hline
\end{tabular}

${ }^{*} P$ values using $\chi^{2}$ tests.

†The $\mathrm{p}$ values are obtained from mixed logistic regression models adjusting for potential clustering within the facilities attended.

$\mathrm{PHC}$, primary healthcare.

medical devices', 'wait time', health insurance and 'cost of service', 'cleanliness and tidiness of the facility' ( $p<0.05$ for all, see table 3 ).

Compared with public PHC patients, persons attending private outpatient clinics were more likely to report 'availability of medical devices', 'privacy and personal
Information respected' and 'cleanliness and tidiness of the facility' as influential reasons to use the respective medical institution ( $\mathrm{p}<0.001$, table 3$)$. On the other hand, only $28 \%$ of people attending private clinics reported that the affordable cost of services was an important factor for them to utilise the respective service and only for $36 \%$ of 


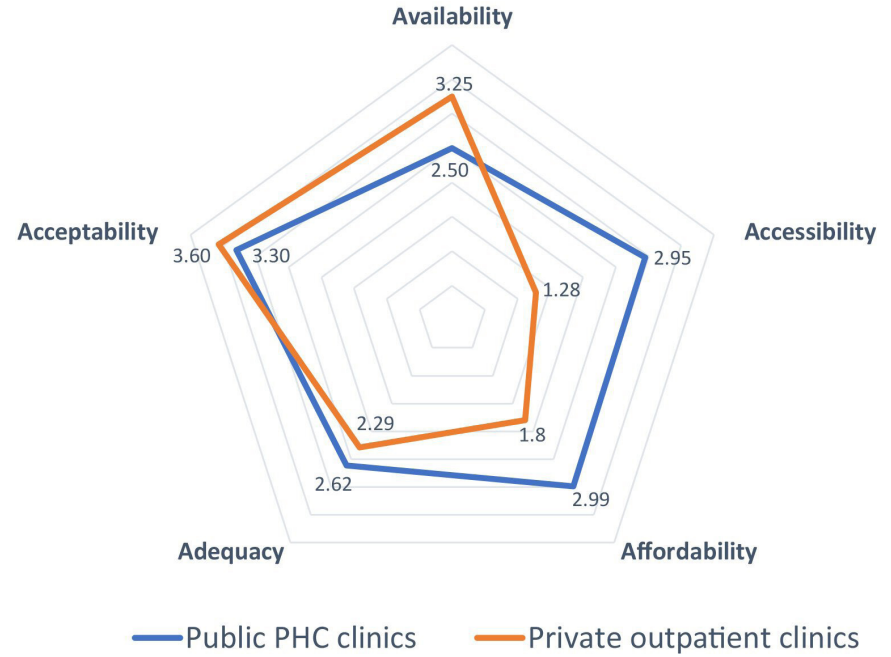

Figure 3 Radar chart plots: mean scores of access domains in patients of public and private clinics. PHC, primary healthcare.

them said short wait time having been an important criterion, while the respective percentages were $73 \%$ and $64 \%$ among attendants of PHC's $(p<0.001)$.

Further, 'location of the facility' and 'health insurance' were assigned more importance by public PHC patients than by patients attending private clinics 'users $(\mathrm{p}<0.05$, table 3).

\section{Discriminating mean access domains 'results between public} and private primary care facilities

The two groups of patients had different views on some of the access elements/dimensions. As visualised in radar chart plots (see figure 3), the affordability, accessibility and availability domains differed most between patients of the two groups. Patients attending public PHC clinics rated access elements (items) significantly higher than those attending private clinics, who, in turn, considered availability items as more important. Adequacy and acceptability items were evaluated similarly by both groups of patients.

\section{Individual factors associated with patients' utilisation of public and private settings}

Table 4 shows the ORs of using public PHC facilities vs private health facilities associated with different individual factors. The odds of using public facilities were significantly higher among the patients who perceived their health as poor (OR 5.59; 95\% CI 2.62 to 11.92) and among those who were benefiting from a socioeconomic aid scheme (OR 3.52; 95\% CI 1.64 to 7.56). Patients suffering from two or more chronic conditions had higher odds of using governmental PHC facilities (OR 3.13; 95\% CI 1.36 to 7.24) compared with those that reported no or just one chronic health condition. Women were less likely than men to use public facilities (OR 0.64; $95 \%$ CI 0.40 to 1.04 ).
Table 4 ORs of attending a public health facility associated with different patient characteristics

\begin{tabular}{|c|c|c|c|}
\hline Variables/factors & OR & $P$ value & $95 \% \mathrm{Cl}$ \\
\hline \multicolumn{4}{|l|}{ Gender } \\
\hline Female & $0.64+$ & 0.07 & 0.40 to 1.04 \\
\hline \multicolumn{4}{|l|}{ Age } \\
\hline$>60$ years & 0.73 & 0.46 & 0.32 to 1.68 \\
\hline \multicolumn{4}{|l|}{ Education } \\
\hline High school (12 years) & 0.96 & 0.9 & 0.50 to 1.86 \\
\hline Primary 9 years) & 0.79 & 0.49 & 0.40 to 1.55 \\
\hline Other & 1.95 & 0.59 & 0.18 to 21.3 \\
\hline \multicolumn{4}{|l|}{ Occupation } \\
\hline Unemployed & 1.1 & 0.76 & 0.61 to 1.98 \\
\hline Pensioner & 0.85 & 0.71 & 0.35 to 2.04 \\
\hline \multicolumn{4}{|c|}{ Benefiting socioeconomic aid } \\
\hline Yes & 3.52 & 0 & 1.64 to 7.56 \\
\hline \multicolumn{4}{|l|}{ Health insurance } \\
\hline Insured & 1.35 & 0.3 & 0.76 to 2.38 \\
\hline \multicolumn{4}{|l|}{ Chronic conditions } \\
\hline 1 chronic cond. & 1.22 & 0.53 & 0.66 to 2.25 \\
\hline 2 or more chronic cond & $3.13^{*}$ & 0.01 & 1.36 to 7.24 \\
\hline \multicolumn{4}{|l|}{ Health condition } \\
\hline Poor health & 5.59 & 0 & 2.62 to 11.9 \\
\hline
\end{tabular}

*Statistically significant+by-trend statistically significant, $p=0.07+$; ORs were obtained from a mixed logistic regression model including all the variables listed in the table along with random intercepts for the three subterritorial divisions of Fier region.

\section{DISCUSSION}

In the present survey, we asked patients who consulted a public or private provider through an exit interview to rank the importance of the items that influenced their decision to use the respective facilities. Common and discriminating items (factors) and relevant sociodemographic characteristics associated with the priority for a given facility type are described and discussed according to their importance, relevance and context, guided by the access framework.

\section{'Perceived quality of care' and 'attitudes of healthcare providers'}

The results of this survey show that 'quality of care', and 'healthcare professionals' attitudes were the most important criteria influencing the choice of the type of health facility for public and private health facility users alike. Irrespective of the health facility type, patients rated good quality of care and qualified, courteous healthcare staff among their principal reasons for using the respective type of healthcare facility, while their rating of other aspects of care such as cost of service, health insurance or choice of doctor differed. These results are in line with previous research findings, indicating that quality of care matters and frequently overrules other factors influencing 
healthcare service utilisation. ${ }^{2637-39}$ This also suggests that further improvements of quality of PHC care in Albania might have a positive impact on boosting PHC utilisation, which may be particularly relevant for targeted populations such as women, patients with chronic health conditions, patients benefiting from socialeconomic aid and elderly people. ${ }^{18} 19$

Although an increase in the number of doctors available in a community results in an increase in healthcare utilisation of all types, ${ }^{40}$ the mere availability of a provider will not imply that the facility will be used and proper care will be obtained. Often, utilisation of health services is a product of dynamic interactions between providers and patients, where health professionals' communication skills, supportive non-judgmental behaviour and empathy further facilitates/drives the health service utilisation.

Previous research has shown that poor health worker attitudes or practices negatively influence the quality of services and decreased utilisation of facilities. ${ }^{41}$ On the other hand, skills and competence of the care provider play a significant role in service utilisation. ${ }^{27} 37$ Training programmes, empowering health professionals with formal quality improvement methods and patient-centred communication skills, have proven to increase the quality of healthcare as seen by patients. ${ }^{28}$

\section{'Geographical proximity' and 'availability of medical devices'} In this study, notable differences were identified regarding the importance of specific items/factors for the choice of the type of health facility between patients attending public and private clinics. Our results suggest that having access to a facility which is close to the dwellings is an important factor for patients attending public PHCs. Linking health facilities to populations has been a traditional index of healthcare coverage. Previous studies have shown that access to health facilities as characterised in terms of location or transportation means were important factors influencing health service utilisation. ${ }^{39} 4243$ Additional evidence from the literature shows that the differential distribution of financial resources, lack of transport means disfavours the poorest and negatively influences utilisation of health services. Thus, efforts of improving geographical access to PHCs in Albania might primarily lead to higher utilisation rates in periurban areas, while access might still be impeded in rural and remote areas with mountainous environments where transport means are severely restricted (in terms of availability or affordability).

Within the present study, only $11 \%$ of patients who attended a private outpatient clinic ranked the location of the facility as an important factor. An explanation might be that the private clinic users are willing to travel longer distances and consider that their healthcare needs are better met in a private clinic. In fact, $67 \%$ of the users of the private outpatient clinics viewed 'availability of medical devices' as an important (or very important) factor motivating them to attend a private outpatient clinic. According to our study results, availability of functional and modern medical equipment and ancillary facilities may partly explain why patients choose to use private outpatient clinics. This also confirms that private outpatient clinics are better equipped with adequate medical equipment. Consistent with several studies, other research conducted in Albania also indicates that public PHC have lacked proper medical equipment. ${ }^{14}$ A study conducted in 550 health cetres in 2014 found that only slightly more than half of the health centres (57\% of the total sample) were 'properly equipped' with medical equipment and only about half of health centres were properly stocked with the respective relevant medications. ${ }^{16}$

However, commitment to upgrade PHC in terms of infrastructure and equipment was made through health policy in cooperation with several partners operating in the health sector. This has resulted in a range of investments towards health facilities and maintenance on the recent years. ${ }^{44}$ Thus, in the time frame of $2015-2018,{ }^{44}$ several rehabilitations of infrastructure, and procurement of basic essential equipment for doctors and nurse and health professional continuous education activities were done, especially in Fier, Diber ${ }^{44}$ and in Tirana. ${ }^{45}$ Based on a survey conducted in 2018, there has been substantial improvements on availability of basic equipment and transparency and public accountability. ${ }^{44}$

Moreover, a programme of rehabilitation of 300 health centres across the whole country and building 80 new facilities is currently in place from the Ministry of Health and Social Protection. ${ }^{46}$

\section{'Wait time'}

In our study, wait time was not among the most important factors determining the choice of health facility type neither among patients from public nor among patients from private clinics. Governmental PHC services in Albania are typically not perceived as extremely busy and hence the waiting time is usually relatively manageable for users. Moreover, the waiting time was rated almost equally across respondents irrespective to employment status or age category. Previous research indicates that excessive wait times deter the use of health services and may sometimes result from the inefficient use of existing capacity or a failure to design services around the needs of patients. ${ }^{47}$

\section{Sociodemographic and health gradients}

Regarding sociodemographic and health-related characteristics associated with utilisation of each provider type, we found that females were more likely to use private clinics than men. This could be explained with the availability of the medical equipment and diagnostics (eg, for gynaecological services); patients who chose private outpatient clinics were also more likely to assess their health status as better compared with users of public PHC centres. This is contrary to other studies, having found that a significantly higher percentage of patients having 
chosen private settings perceived their health status as poor. ${ }^{12} 353648$

This study found that having two or more chronic health conditions was significantly associated with public PHC care utilisation. This might suggest that several NCDs are mainly being treated at the PHC level in Albania. Moreover, these findings may support existing evidence that people with chronic diseases are primarily patronised by the public healthcare sector. ${ }^{49} \mathrm{~A}$ review of additional literature suggests inconsistent results on whether perceived severity of condition or quality of care are driving factors for choosing private care over other healthcare options. ${ }^{1235} 364850$

\section{Private outpatient clinics utilisation: Is there a choice or a need?}

A choice between public and private providers is of less importance than the ability to choose between different treatments and to access reliable services that are responsive to patients' preferences. ${ }^{485152}$ Our results might imply that patients used the private sector because of diagnostic services. The governmental health insurance fund does not contract all private outpatient clinics, except with few selected private hospitals. As a result, they are not accessible to poor people or members of other marginalised and vulnerable groups who lack the money to pay for them.

Furthermore, private providers who provide care for patients who have previously consulted public facilities before (PHC or hospitals) cannot fully access patients' public electronic health records as the public sector is currently not equipped with a well-developed, central national electronic patient record system, pooling information both from public and private healthcare providers. This raises concerns about potentially excessive procedures and medical tests that patients have to go through once they visit private practitioners or outpatient clinics of the private hospitals.

Our study, based on patient's ranking, contradicts the claim that the public sector appears frequently to lack timeliness or quality ${ }^{35}$; however, the private sector, like in other studies, is positively perceived as offering better hospitality towards patients in terms of basic amenities or medical supplies. ${ }^{48}$

The private sector utilisation in PHC poses significant challenges and opportunities in terms of the safety, effectiveness and cost of health services. Engaging the private sector to improve PHC within UHC is a complex, multifaceted endeavour and its' importance is greater for PHC; thus, detailing the rationale for engaging the sector is a vital early step ${ }^{38}$

\section{CONCLUSIONS}

This study is one of the first in Albania having analysed individual and health system-related factors influencing health care-seeking- behaviour among patients from public and private outpatient facilities.
The study identified 'perceived quality of care', 'availability of qualified staff' and 'staff courtesy' as important criteria for the choice of health facility, irrespective of whether patients attended a public or a private facility. The two groups of patients differed in their view of the importance of 'location of facility', which was evaluated as important by the majority of patients attending public PHCs but only by a minority of patients from private clinics. Conversely, the 'availability of medical equipment' was considered as important by private clinic users.

Sociodemographics and health gradients were also associated with the type of healthcare provider chosen. Users of public PHCs were more likely to report chronic health conditions.

Seeking care from public PHCs providers was strongly associated with financial access to health services such as dependency on a form of socioeconomic aid scheme.

Although equipment availability has substantially improved in the time period of 2015-2018 in the region where the study was conducted, efforts to further upgrade medical equipment and associated workforce skills are needed to sustainably increase access to and utilisation of public PHCs. Moreover, in the light of the new administrative and territorial reform in Albania (2015) ${ }^{53}$ where municipalities have the possibility to do assessment of local service, rehabilitation and maintenance of facilities, and evaluation of educational and promotional activity at a local level, there is need for strong commitment of all stakeholders, such as local decision makers, professional associations to support and to invest into public PHC.

Acknowledgements We would like to thank the team of the 'Health for All Project' (Projekti HAP) for their support on the field work. Special thanks to Sabine Kiefer, Altina Peshkatari \& Manuela Murthi, the regional coordinators of Fier and Diber region and data collectors for their outstanding contribution.

Contributors Conceptualisation: JG and KW; Data curation: JG and CS; Formal analysis: JG and CS; Methodology: JG and CS; Writing —original draft: JG; Review and editing: CS and KW. KW made a substantial contribution to critically revising the manuscript for important intellectual content. All authors contributed substantially to the manuscript and agreed to the final version.

Funding The study has been conducted in the frame of the 'Health for All Project' (Projekti HAP http://www.hap.org.al/) funded by the Swiss Agency for Development and Cooperation (SDC) and implemented by the Swiss Tropical and Public Health Institute. The first author is supported by a Swiss Government Excellence Scholarship (2017.0655).

Competing interests None declared.

Patient and public involvement Patients and/or the public were involved in the design, or conduct, or reporting, or dissemination plans of this research. Refer to the Methods section for further details.

Patient consent for publication Not required.

Ethics approval The study protocol was approved by the ethics committee of north-western and central Switzerland (EKNZ- Ethikkommission Nordwest- und Zentralschweiz), No. 30 715. The study also received clearance by the National Ethics Committee of Albania, nr.55, date 8 June 2018.

Provenance and peer review Not commissioned; externally peer reviewed.

Data availability statement Data are available on reasonable request. Data are available on reasonable request and approval by the authors and involved project partners.

Open access This is an open access article distributed in accordance with the Creative Commons Attribution Non Commercial (CC BY-NC 4.0) license, which permits others to distribute, remix, adapt, build upon this work non-commercially, 
and license their derivative works on different terms, provided the original work is properly cited, appropriate credit is given, any changes made indicated, and the use is non-commercial. See: http://creativecommons.org/licenses/by-nc/4.0/.

\section{ORCID iD}

Jonila Gabrani http://orcid.org/0000-0002-8732-8193

\section{REFERENCES}

1 Stigler FL, Macinko J, Pettigrew LM, et al. No universal health coverage without primary health care. Lancet 2016;387:1811.

2 Kringos DS, Boerma WGW, Hutchinson A, et al. Building primary care in a changing Europe, 2015. Available: http://www.euro.who. int/en/about-us/partners/observatory/publications/studies/buildingprimary-care-in-a-changing-europe

3 Kruk ME, Gage AD, Joseph NT, et al. Mortality due to lowquality health systems in the universal health coverage era: a systematic analysis of amenable deaths in 137 countries. Lancet 2018;392:2203-12.

4 Bitton A, Ratcliffe HL, Veillard JH, et al. Primary health care as a foundation for strengthening health systems in low- and middleincome countries. J Gen Intern Med 2017;32:566-71.

5 Aday LA, Andersen R. A framework for the study of access to medical care. Health Serv Res 1974;13.

6 Penchansky R, Thomas JW. The concept of access: definition and relationship to consumer satisfaction. Med Care 1981;19:127-40.

7 Peters DH, Garg A, Bloom G, et al. Poverty and access to health care in developing countries. Ann N Y Acad Sci 2008;1136:161-71.

8 Levesque J-F, Harris MF, Russell G. Patient-centred access to health care: conceptualising access at the interface of health systems and populations. Int J Equity Health 2013;12:18.

9 Saurman E. Improving access: modifying Penchansky and Thomas's theory of access. J Health Serv Res Policy 2016;21:36-9.

10 Russell DJ, Humphreys JS, Ward B, et al. Helping policy-makers address rural health access problems. Aust $J$ Rural Health 2013;21:61-71.

11 Comino EJ, Davies GP, Krastev Y, et al. A systematic review of interventions to enhance access to best practice primary health care for chronic disease management, prevention and episodic care. BMC Health Serv Res 2012;12:415.

12 Tang $\mathrm{C}$, Xu J, Zhang M. The choice and preference for publicprivate health care among urban residents in China: evidence from a discrete choice experiment. BMC Health Serv Res 2016;16:580.

13 Nuri B, Tragakes E. Health care systems in transition: Albania. Eur Obs Health Care Syst 2002;46:102.

14 The Regional Office for Europe of the World Health Organization. Primary health care in Albania: rapid assessment, 2018. Available: http://www.euro.who.int/en/countries/albania/publications/primaryhealth-care-in-albania-rapid-assessment

15 Sentell TL, Ylli A, Pirkle CM, et al. Promoting a culture of prevention in Albania: the "Si Je?" program. Prevent Sci 2018;372.

16 Arqimandriti M, Ivkoviç M, Naskidashvili I, et al. Monitoring of the primary health care system in Albania, 2014. Available: https://www. usaid.gov/sites/default/files/documents/1863/KZLN-FinalReport-\% 20EN\%20-\%20FINAL\%20LES\%20.pdf

17 Compulsory Healthcare Insurance Fund. Annual report, 2013. Available: https://www.fsdksh.com.al/images/stories/publikimet/ botimet/ANNUAL\%20REPORT_2013.pdf

18 Ministry of Health and Social Protection. Albanian National health strategy 2016-2020. Available: https://shendetesia.gov.al/wpcontent/uploads/2019/01/Health-Strategy-2020 eng.pdf

19 Ministry of Health. National program on prevention and control of NCDS in Albania 2016-2020| ICCP portal. Available: https://www iccp-portal.org/national-program-prevention-and-control-ncdsalbania

20 Bruijn B, Filipi G, Nesturi M, et al. Population ageing: situation of elderly people in Albania, 2015.

21 Fondi i Sigurimit të Detyrueshëm të Kujdesit Shëndetësor. Panoramë e përgjithshme - Fondi i Sigurimit të Detyrueshëm të Kujdesit Shëndetësor. Available: https://www.fsdksh.com.al/fsdksh/ panorame-e-pe-rgjithshme

22 Ministry of Health. Albania, health system overview. presented at the: Ministry of health, Albania. Available: http://www.vhpb.org/files/html/ Meetings_and_publications/Presentations/ALB92.pdf

23 What kind of evidence do we need to strengthen primary healthcare in the 21 st century? what kind of evidence do we need to strengthen primary healthcare in the 21st century? 2019. Available: https:// lastmilehealth.org/bmj-phc-editorial/ [Accessed 17 Sept 2019].
24 Field KS, Briggs DJ. Socio-Economic and locational determinants of accessibility and utilization of primary health-care. Health Soc Care Community 2001;9:294-308.

25 O'Donnell O. Access to health care in developing countries: breaking down demand side barriers. Cad Saude Publica 2007;23:2820-34.

26 Gage AD, Leslie HH, Bitton A, et al. Does quality influence utilization of primary health care? Evidence from Haiti. Global Health 2018;14:59

27 Tancred T, Schellenberg J, Marchant T. Using mixed methods to evaluate perceived quality of care in southern Tanzania. Int J Qual Health Care 2016;28:233-9.

28 Nørgaard B, Kofoed P-E, Ohm Kyvik K, et al. Communication skills training for health care professionals improves the adult orthopaedic patient's experience of quality of care. Scand J Caring Sci 2012;26:698-704.

29 Obrist B, Iteba N, Lengeler C, et al. Access to health care in contexts of livelihood insecurity: a framework for analysis and action. PLoS Med 2007; 4:e308.

30 Kumar A, Singh K, Krishnamurthy K, et al. Exploring the role of the public and private funded primary health care facilities for children in a Pluralistic health care setting of Barbados: one of the English Caribbean countries. Int J Prev Med 2015;6.

31 Levesque J-F, Haddad S, Narayana D, et al. Outpatient care utilization in urban Kerala, India. Health Policy Plan 2006;21:289-301.

32 Balabanova D, Roberts B, Richardson E, et al. Health care reform in the former Soviet Union: beyond the transition. Health Serv Res 2012;47:840-64

33 Peabody JW, DeMaria L, Smith O, et al. Large-Scale evaluation of quality of care in 6 countries of eastern Europe and central Asia using clinical performance and value Vignettes. Glob Health Sci Pract 2017;5:412-29.

34 Liu Y, Zhong L, Yuan S, et al. Why patients prefer high-level healthcare facilities: a qualitative study using focus groups in rural and urban China. BMJ Glob Health 2018;3:e000854.

35 Basu S, Andrews J, Kishore S, et al. Comparative performance of private and public healthcare systems in low- and middle-income countries: a systematic review. PLoS Med 2012;9:e1001244.

$36 \mathrm{Kim}$ AM, Cho S, Kim HJ, et al. Rethinking the role of the public health clinic: comparison of outpatient utilization in the public health clinics and private clinics in Korea. Int $J$ Environ Res Public Health 2018;15

37 Identifying role of perceived quality and satisfaction on the utilization status of the community clinic services; Bangladesh context | BMC health services research | full text. Available: https:// bmchealthservres.biomedcentral.com/articles/10.1186/s12913-0161461-z [Accessed 7 Oct 2019].

38 Oladipo JA. Utilization of health care services in rural and urban areas: a determinant factor in planning and managing health care delivery systems. Afr Health Sci 2014;14:322-33.

39 Okonofua F, Ntoimo L, Ogungbangbe J, et al. Predictors of women's utilization of primary health care for skilled pregnancy care in rural Nigeria. BMC Pregnancy Childbirth 2018;18:106.

40 Jin Y, Zhu W, Yuan B, et al. Impact of health workforce availability on health care seeking behavior of patients with diabetes mellitus in China. Int J Equity Health 2017;16:80.

41 Bakeera SK, Wamala SP, Galea S, et al. Community perceptions and factors influencing utilization of health services in Uganda. Int $J$ Equity Health 2009;8:25.

42 Syed ST, Gerber BS, Sharp LK. Traveling towards disease: transportation barriers to health care access. J Community Health 2013;38:976-93 https://www.ncbi.nlm.nih.gov/pubmed/23543372

43 Dassah E, Aldersey H, McColl MA, et al. Factors affecting access to primary health care services for persons with disabilities in rural areas: a "best-fit" framework synthesis. Glob Health Res Policy 2018;3:36.

44 HAP. Reports \& Studies. Available: http://www.hap.org.al/en/rapotedhe-studime/ [Accessed 7 May 2020].

45 New primary health care center for the community in Laprake, Tirana | Albania | save the children. Available: https://albania. savethechildren.net/news/new-primary-health-care-center-forcommunity-laprake-tirana [Accessed 7 May 2020].

46 Vata I. Investimet në Shëndetësi, $14 \mathrm{mln}$ euro me shumë për vitin 2018 - ATSH -. Agjencia Telegrafike Shqiptare, 2018https://ata.gov al/2018/09/06/investimet-ne-shendetesi-14-mln-euro-me-shumeper-vitin-2018/ [Accessed 7 May 2020].

47 Gulliford M, Morgan M. Access to health care. Routledge, 2013.

48 Berendes S, Heywood P, Oliver S, et al. Quality of private and public ambulatory health care in low and middle income countries: systematic review of comparative studies. PLoS Med 2011;8:e1000433.

49 Kiefer S. Access to health services in Diber and Fier regions. 114 
50 McPhail SM. Multimorbidity in chronic disease: impact on health care resources and costs. Risk Manag Healthc Policy 2016;9:143-56.

51 Engaging the Private Sector in PHC to Achieve UHC. Advice from Implementers to Implementers | joint learning network. Available: https://www.jointlearningnetwork.org/resources/phc-engaging-theprivate-sector-in-phc-to-achieve-uhc/
52 Mackintosh M, Channon A, Karan A, et al. What is the private sector? understanding private provision in the health systems of low-income and middle-income countries. Lancet 2016;388:596-605.

53 Për Vetëqeverisjen Vendore. Available: http://www.erru.al/doc/ Ligj_nr.139-2015_date_17.12.2015_Per_vetqeverisjen_vendore.pdf [Accessed 8 May 2020]. 